\title{
水平板による防波堤と岸壁に関する理論的研究 (2)
}

井島 武士* - 尾崎 重雄** - 江口 泰彦*** 一小林 彰****

\section{1.はしがき}

前報告“直立消波岸壁に関する研究 (I )”に扔いて, 水平板をもつ岸壁に対する波の作用について述べたが, それは理論的には水面に固定された水平板に対する波の 作用として取扱らことができる。本論文では完全流体の 微小振幅波に対し，水平板が 1 枚の場合と 2 枚の場合お よび水平板の下部に空げきと抵抗をもつ物質（たとえば 捨石など）が填允されている場合の取扱いと計算の結果 を述べる。

\section{2. 水平板による防波堤の理論}

図一1 に示すように一定水深 $h$ の流体域の表面に長 さ $2 l$ の剛体板が固定されているとし, 座標系を図のよ うにとり，流体域を $x= \pm l$ で分け， $x \geq l$ を領域 $\mathrm{I}$, $l \geqq x \geqq-l$ を領域 III， $x \leqq-l$ を領域 III とする。各領 域における速度ポテンシャルをそれぞれ $\phi_{1}, \phi_{2}$ 抢上び $\phi_{3}$ とすると, それらは Laplace の方程式を満足せ称ば ならない。すなわち

$$
\frac{\partial^{2} \phi_{i}}{\partial x^{2}}+\frac{\partial^{2} \phi_{i}}{\partial z^{2}}=0 \quad(i=1,2,3)
$$

領域Ｉ とに打ける水底および氷面条件は次のようで ある。

$$
z=-h \text { で } \frac{\partial \phi_{i}}{\partial z}=0 ; \quad z=0 \text { で }
$$$$
\frac{\partial^{2} \phi_{i}}{\partial t^{2}}+g \frac{\partial \phi_{i}}{\partial z}=0, \quad(i=1,3)
$$

領域IIで法次の条件となる。

$$
z=-h \text { で } \frac{\partial \phi_{2}}{\partial z}=0 ; \quad z=0 \text { で } \frac{\partial \phi_{2}}{\partial z}=0 \cdots(3)
$$

各領域での流体内の圧力と領域 I，III の水面波形はそ れぞれ次式で表わされる。

$$
\begin{gathered}
\frac{p_{i}}{\rho}=-\frac{\partial \phi_{i}}{\partial t}-g z, \quad(i=1,2,3) ; \\
\zeta_{i}=-\frac{1}{g}\left(\frac{\partial \phi_{i}}{\partial t}\right)_{z=0}(i=1,3) \cdots
\end{gathered}
$$

上の各式で $g$ は重力の加速度である。

領域 $\mathrm{I}$ では周波数 $\sigma(=2 \pi / T, T$ は周期 $)$ の入射波と 反射波，領域亚では通過波があるとすると各領域で水底 および水面条件を満足する速度ポテンシャルは次式で与 えられる。

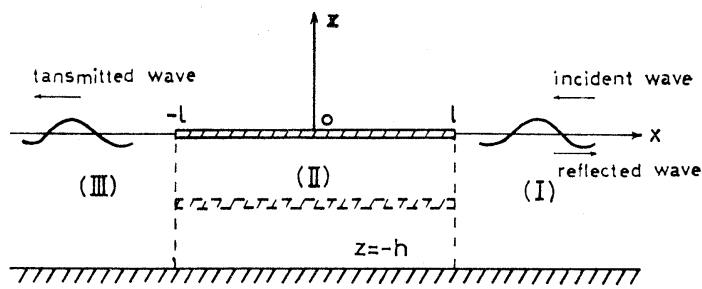

図-1 Breakwater by Horizontal Plate

$$
\begin{aligned}
& \phi_{1}(x, z ; t)=e^{i \sigma t}\left[\left(A e^{i k x}+B e^{-i k x}\right) \frac{\cosh k(z+h)}{\cosh k h}+\sum_{n=1}^{\infty} C_{n} e^{-k_{n} x} \frac{\cos k_{n}(z+h)}{\cos k_{n} h}\right] \\
& \phi_{2}(x, z ; t)=e^{i \sigma t} \sum_{r=0}^{\infty}\left(D_{r} \cosh \frac{r \pi x}{h}+E_{r} \sinh \frac{r \pi x}{h}\right) \cos \frac{r \pi z}{h}, \quad(r=0,1,2 \cdots \cdots) \cdots \cdots \\
& \phi_{3}(x, z ; t)=e^{i \sigma t}\left[F e^{i k x} \frac{\cosh k(z+h)}{\cosh k h}+\sum_{n=1}^{\infty} G_{n} e^{k_{n} x} \frac{\cos k_{n}(z+h)}{\cos k_{n} h}\right] \ldots \ldots \ldots \ldots \ldots \ldots \ldots \ldots \ldots \ldots \ldots
\end{aligned}
$$

式 (5)，(7) における $k$ および $k_{n}$ は次式により決

* 正会員 工博 九州大学教授 工学部水工士木工学科

** 正会員 前運輸省第 4 港湾建設局長

*** 正会員 九州大学助手 工学部水工士木工学科 九州大学工学部研究補助員
まる微分方程式の固有值である。

$$
\begin{aligned}
\frac{\sigma^{2} h}{g} & =k h \tanh k h \\
& =-k_{n} h \tan k_{n} h, \quad(n=1,2, \cdots \cdots)
\end{aligned}
$$

$A, B$ および $F$ はそれぞれ入射波, 反射波㧍よび通 過波を表わす定数で, $C_{n}$ と $G_{n}$ は $|x| \rightarrow \infty$ で消滅する 
定常波である。式 (6) の $D_{r}, E_{r}$ は境界条件で決まる 定数で $r$ は整数である。

各領域の境界 $x= \pm l$ では質量およびエネルギー流束 の連続により，水平流速と圧力の連続性が成立すべきで あるから，次の条件式が満足されねばならない。

$$
\begin{aligned}
& x=l \text { で } \frac{\partial \phi_{1}}{\partial x}=\frac{\partial \phi_{2}}{\partial x}, \phi_{1}=\phi_{2} \cdot \\
& x=-l \text { で } \frac{\partial \phi_{2}}{\partial x}=\frac{\partial \phi_{3}}{\partial x}, \phi_{2}=\phi_{3}
\end{aligned}
$$

式（9)，(10) に式（5)，(6)，(7) を代入すると 次の各式を得る。

$$
\begin{aligned}
& \left(A e^{i k l}-B e^{-i k l}\right) \frac{\cosh k(z+h)}{\cosh k h}+i \sum_{n=1}^{\infty} C_{n} e^{-k_{n} l} \frac{k_{n} \cos k_{n}(z+h)}{k \cos k_{n} h} \\
& =-i \sum_{r=0}^{\infty} \frac{r \pi}{k h}\left(D_{r} \sinh \frac{r \pi l}{h}+E_{r} \cosh \frac{r \pi l}{h}\right) \cos \frac{r \pi z}{h} \\
& \left(A e^{i k l}+B e^{-i k l}\right) \frac{\cosh k(z+h)}{\cosh k h}+\sum_{n=1}^{\infty} C_{n} e^{-k_{n} l} \frac{\cos k_{n}(z+h)}{\cos k_{n} h}=\sum_{r=0}^{\infty}\left(D_{r} \cosh \frac{r \pi l}{h}+E_{r} \sinh \frac{r \pi l}{h}\right) \cos \frac{r \pi z}{h} . . \\
& F e^{-i k l} \frac{\cosh k(z+h)}{\cosh k h}-i \sum_{n=1}^{\infty} G_{n} e^{-k_{n} l} \frac{k_{n} \cos k_{n}(z+h)}{k \cos k_{n} h} \\
& =-i \sum_{r=0}^{\infty} \frac{r \pi}{k h}\left(-D_{r} \sinh \frac{r \pi l}{h}+E_{r} \cosh \frac{r \pi l}{h}\right) \cos \frac{r \pi z}{h}
\end{aligned}
$$

式（11）と（13）および式（13）と（15）を加えまたは差し引くと次式を得る。

$$
\begin{aligned}
& \left\{A e^{i k l}-(B-F) e^{-i k l}\right\} \frac{\cosh k(z+h)}{\cosh k h}+i \sum_{n=1}^{\infty}\left(C_{n}-G_{n}\right) e^{-k_{n} l} \frac{k_{n} \cos k_{n}(z+h)}{k \cos k_{n} h} \\
& =-2 i \sum_{r=0}^{\infty} \frac{r \pi}{k h} E_{r} \cosh \frac{r \pi l}{h} \cos \frac{r \pi z}{h} \\
& \left\{A e^{i k l}+(B-F) e^{-i k l}\right\} \frac{\cosh k(z+h)}{\cosh k h}+\sum_{n=1}^{\infty}\left(C_{n}-G_{n}\right) e^{-k_{n} l} \frac{\cos k_{n}(z+h)}{\cos k_{n} h}=2 \sum_{r=0}^{\infty} E_{r} \sinh \frac{r \pi l}{h} \cos \frac{r \pi z}{h} \\
& \left\{A e^{i k l}-(B+F)-e^{i k l}\right\} \frac{\cosh k(z+h)}{\cosh k h}+i \sum_{n=1}^{\infty}\left(C_{n}+G_{n}\right) e^{-k_{n} l} \frac{k_{n}}{k} \frac{\cos k_{n}(z+h)}{\cos k_{n} h} \\
& =-2 i \sum_{r=0}^{\infty} \frac{r \pi}{k h} D_{r} \sinh \frac{r \pi l}{h} \cos \frac{r \pi z}{h} \\
& \left\{A e^{i k l}+(B+F) e^{-i k l}\right\} \frac{\cosh k(z+h)}{\cosh k h}+\sum_{n=1}^{\infty}\left(C_{n}+G_{n}\right) e^{-k_{n} l} \frac{\cos k_{n}(z+h)}{\cos k_{n} h}=2 \sum_{r=0}^{\infty} D_{r} \cosh \frac{r \pi l}{h} \cos \frac{r \pi z}{h} .
\end{aligned}
$$

上の各式に $\cos (r \pi z / h)$ を乗じ $z=-h$ から 0 まで積分すると

$$
\begin{aligned}
& \int_{-h}^{o} \cos \frac{s \pi z}{h} \cos \frac{r \pi z}{h} d z=0(r \neq s) ;=h / 2(r=s \neq 0) ;=h(r=s=0) \\
& \int_{-h}^{o} \cosh k(z+h) \cos \frac{r \pi z}{h} d z=\frac{1}{k} \cdot \frac{\sinh k h}{1+\left(\frac{r \pi}{k h}\right)^{2}}, \int_{-h}^{o} \cos k_{n}(z+h) \cos \frac{r \pi z}{h} d z=\frac{1}{k_{n}} \cdot \frac{\sin k_{n} h}{1-\left(\frac{r \pi}{k_{n} h}\right)^{2}}
\end{aligned}
$$

の関係があるから式 (15)〜 (18) から次式を得る。

$$
\left\{A e^{i k l}-(B-F) e^{-i k l}\right\} \frac{\tanh k h}{1+\left(\frac{r \pi}{k h}\right)^{2}}+i \sum_{n=1}^{\infty}\left(C_{n}-G_{n}\right) e^{-k_{n} l} \frac{\tan k_{n} h}{1-\left(\frac{r \pi}{k_{n} h}\right)^{2}}=-i r \pi E_{r} \cosh \frac{r \pi l}{h}
$$




$$
\begin{aligned}
& \left\{A e^{i k l}+(B-F) e^{-i k l}\right\} \frac{\tanh k h}{1+\left(\frac{r \pi}{k h}\right)^{2}}+\sum_{n=1}^{\infty}\left(C_{n}-G_{n}\right) e^{-k_{n} l} \frac{k}{k_{n}} \frac{\tan k_{n} h}{1-\left(\frac{r \pi}{k_{n} h}\right)^{2}}=k h E_{r} \sinh \frac{r \pi l}{h} . \\
& \left\{A e^{i k l}-(B+F) e^{-i k l}\right\} \frac{\tanh k h}{1+\left(\frac{r \pi}{k h}\right)^{2}}+i \sum_{n=1}^{\infty}\left(C_{n}+G_{n}\right) e^{-k_{n} l} \frac{\tan k_{n} h}{1-\left(\frac{r \pi}{k_{n} h}\right)^{2}}=-i r \pi D_{r} \sinh \frac{r \pi l}{h} \cdots \\
& \left\{A e^{i k l}+(B+F) e^{-i k l}\right\} \frac{\tanh k h}{1+\left(\frac{r \pi}{k h}\right)^{2}}+\sum_{n=1}^{\infty}\left(C_{n}+G_{n}\right) e^{-k_{n} l} \frac{k}{k_{n}} \frac{\tan k_{n} h}{1-\left(\frac{r \pi}{k_{n} h}\right)^{2}}=k h D_{r} \cosh \frac{r \pi l}{h} .
\end{aligned}
$$

上式からそれぞれ $E_{r}$ および $D_{r}$ を消去し

$$
\begin{aligned}
& A e^{i k l}=a, B e^{-i k l}=b, F e^{-i k l}=f, C_{n} e^{-k_{n} l}=C_{n}, G_{n} e^{-k_{n} l}=g_{n}, \frac{\pi l}{h}=H, \frac{k h}{\pi}=\lambda_{0}, \frac{k_{n} h}{\pi}=\lambda_{n}, \\
& F_{r, n}=\frac{\lambda_{0}{ }^{2}+r^{2}}{\lambda_{n}{ }^{2}-r^{2}} \cdot \frac{\lambda_{n}+r \tanh r H}{\sqrt{\lambda_{0}{ }^{2}+(r \tanh r H)^{2}}}, \phi_{r, n}=\frac{\lambda_{0}{ }^{2}+r^{2}}{\lambda_{n}{ }^{2}-r^{2}} \cdot-\frac{\lambda_{n}+r \operatorname{coth} r H}{\sqrt{\lambda_{0}{ }^{2}+(r \operatorname{coth} r H)^{2}}}, \\
& \theta_{r}=\tan ^{-1}\left(\frac{r}{\lambda_{0}} \tanh r H\right), \varphi_{r}=\tan ^{-1}\left(\frac{r}{\lambda_{0}} \operatorname{coth} r H\right)
\end{aligned}
$$

とおくと，次の関係式を得る。

$$
\begin{aligned}
& \frac{b+f}{a} \cdot e^{-i \theta_{r}+i} \sum_{n=1}^{\infty} F_{r, n} \cdot \frac{C_{n}+g_{n}}{a}=e^{i \theta_{r}} \quad(r=0,1,2 \cdots \cdots) \\
& \frac{b-f}{a} \cdot e^{-i \varphi_{r}+i} \sum_{n=1}^{\infty} \phi_{r, n}=\frac{C_{n}-g_{n}}{a}=e^{i \varphi_{r}} \quad(r=0,1,2 \cdots \cdots) \cdot
\end{aligned}
$$

とくに $r=0$ に対しては

$$
\begin{aligned}
& \theta_{0}=0, \varphi_{0}=\lim _{r \rightarrow 0} \tan ^{-1}\left(r H \operatorname{coth} r H / \lambda_{0} H\right)=\tan ^{-1}\left(1 / \lambda_{0} H\right) \\
& F_{0, n}=\lambda / \lambda_{n}, \quad \phi_{0, n}=\lim _{r \rightarrow 0} \frac{\lambda_{0}{ }^{2}+r^{2}}{\lambda_{n}{ }^{2}-r^{2}} \cdot \frac{\lambda_{n}+r \operatorname{coth} r H}{\sqrt{\lambda_{n}{ }^{2}+(r \operatorname{coth} r H)^{2}}}=\frac{\lambda_{0}{ }^{2}}{\lambda_{n}{ }^{2}} \cdot \frac{1+\lambda_{n} H}{\sqrt{1+\left(\lambda_{n} H\right)^{2}}}
\end{aligned}
$$

式 (24)，(25) はそれぞれ $(b+f) / a$ と $\left(C_{u}+g_{n}\right) / a_{n}$ および $(b-f) / a$ と $\left(C_{n}-g_{n}\right) / a$ に関する連立 1 次方程式 と見ることができるから，これを解いて $b / a ， f / a, C_{n} / a, g_{n} / a$ を求めることができる。すると式 (20) と (22) から

$$
\begin{aligned}
& D_{0}=\frac{d_{0}}{2}=\frac{a}{2 \pi^{2}} \frac{\sigma^{2} h}{g}\left[\left(1+\frac{b+f}{a}\right) \frac{1}{\lambda_{0}{ }^{2}}-\sum_{n=1}^{\infty} \frac{C_{n}+g_{n}}{a} \frac{1}{\lambda_{n}{ }^{2}}\right] \\
& D_{r} \cosh \frac{r \pi l}{h}=d_{r}=\frac{a}{\pi^{2}} \frac{\sigma^{2} h}{g}\left[\left(1+\frac{b+f}{a}\right) \frac{1}{\lambda_{0}{ }^{2}+r^{2}}-\sum_{n=1}^{\infty} \frac{C_{n}+g_{n}}{a} \frac{1}{\lambda_{n}{ }^{2}-r^{2}}\right] \\
& E_{r} \sinh \frac{r \pi l}{h}=e_{r}=\frac{a}{\pi^{2}} \cdot \frac{\sigma^{2} h}{g}\left[\left(1+\frac{b-f}{a}\right) \frac{1}{\lambda_{0}{ }^{2}+r^{2}}-\sum_{n=1}^{\infty} \frac{C_{n}-g_{n}}{a} \frac{1}{\lambda_{n}{ }^{2}-r^{2}}\right]
\end{aligned}
$$

したがって入射波を $\zeta_{0}=\alpha \cdot \cos (k x+\sigma t)$ とすると

$$
a=i \alpha g e^{i k l} / \sigma
$$

であるから，各領域の速度ポテンシャルは式（5)，(6)，（7）により次のよらに決まる。

$$
\begin{aligned}
& \phi_{1}(x, z ; t)=a e^{i \sigma t}\left[\left\{e^{i k(x-l)}+\frac{b}{a} e^{-i k(x-l)}\right\} \frac{\cosh k(z+h)}{\cosh k h}+\sum_{n=1}^{\infty} \frac{C_{n}}{a} e^{-k_{n}(x-l)} \frac{\cos k_{n}(z+h)}{\cos k_{n} h}\right] \\
& \phi_{2}(x, z ; t)=a e^{i \sigma t}\left[\frac{d_{0}}{2 a}+\sum_{r=1}^{\infty}\left(\frac{d_{r}}{a} \frac{\cosh r H x / l}{\cosh r H}+\frac{e_{r}}{a} \frac{\sinh r H x / l}{\sinh r H}\right) \cos \frac{r \pi z}{h}\right] \\
& \phi_{3}(x, z ; t)=a e^{i \sigma t}\left[\frac{f}{a} e^{i k(x+l)} \frac{\cosh (z+h)}{\cosh k h}+\sum_{n=1}^{\infty} \frac{g_{n}}{a} e^{k_{n}(x+l)} \frac{\cos k_{n}(z+h)}{\cos k_{n} h}\right]
\end{aligned}
$$

領域I と亚の水面波形は次式の実数部分で与えられる。 


$$
\begin{aligned}
& \zeta_{1}(x ; t)=\alpha \cdot e^{i(k l+\sigma t)}\left\{e^{i k(x-l)}+\frac{b}{a} e^{-i k(x-l)}+\sum_{n=1}^{\infty} \frac{C_{n}}{a} e^{-k_{n}(x-l)}\right\} \\
& \zeta_{3}(x ; t)=\alpha \cdot e^{i(k l+\sigma t)}\left\{\frac{f}{a} e^{i k(x+l)}+\sum_{n=1}^{\infty} \frac{g_{n}}{a} e^{k_{n}(x+l)}\right\}
\end{aligned}
$$

反射率を $K_{r}$ ，通過率を $K_{t}$ とすると

$$
K_{r}=|b / a|, K_{t}=|f| a \mid
$$

水平板に作用する流体の圧力は式 (29) の $\phi_{2}$ を式 (4) に用い $z=0$ とおいて次のようである。

$$
\frac{p_{2(z=0)}}{\alpha \rho g}=e^{i(k l+\sigma t)}\left\{\frac{d_{0}}{2 a}+\sum_{r=1}^{\infty}\left(\frac{d_{r}}{a} \frac{\cosh r H x / l}{\cosh r H}+\frac{e_{r}}{a} \frac{\sinh r H x / l}{\sinh r H}\right)\right\}
$$

全圧力を $P_{u}$ とすると

$$
\left|\frac{P_{u}}{\rho g \alpha \cdot 2 l}\right|=\left|\int_{-l}^{l} \frac{p_{2(z=0)}}{\rho g \alpha \cdot 2 l} d x\right|=\mid \frac{d_{0}}{2 a}+\sum_{r=1}^{\infty} \frac{d_{r}}{a} \cdot \frac{\tanh r H}{r H}
$$

\section{3. 水平板をもつ岸壁の理論}

図一2に示すように長さ $l$ の水平板をもつ鈆值壁を 考える。領域 I における条件は前とまったく同じであ り，速度ポテンシャル $\phi_{1}$ 注式（5）で表わされる。領 域IIでは境界条件として式 (3) のほかに $x=0$ で $\partial \phi_{2} /$ $\partial x=0$ が加わることになるから, 式 (6) における定数 $E_{r}$ をすべて 0 とおいて速度ポテンシャルは次のようで ある。

$$
\begin{aligned}
\phi_{2}(x, z ; t)=e^{i \sigma t} \sum_{r=0}^{\infty} D_{r} \cosh \frac{r \pi x}{h} \cos \frac{r \pi z}{h}, \\
\quad(r=0,1,2 \cdots \cdots) \cdots \cdots(35)
\end{aligned}
$$

この 2 つの速度ポテンシャル $\phi_{1}, \phi_{2}$ に対する $x=l$ で の条件は式 (9) と同じである。

前とまったく同じ手続きにより $A e^{i k l}=a, B e^{-i k l}=b$, $C_{n} e^{-k_{n} l}=C_{n}$ とすると式 (23) と同じ記号を用いて $b / a$
と $C_{n} / a$ に関する連立方程式は式 (24) と同じ形で炏の ようである。

$$
\frac{b}{a} e^{-i \theta_{r}}+i \sum_{n=1}^{\infty} F_{r}, n \frac{C_{n}}{a}=e^{i \theta_{r}},
$$

したがって防波堤に対する計算結果がそのまま用いら れ式 (27) に対応して

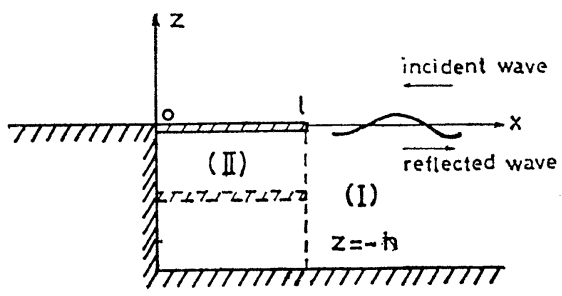

図-2 Quay wall with Horizontal Plate

$$
\begin{aligned}
& D_{0}=\frac{d_{0}}{2}=\frac{a}{\pi^{2}} \cdot \frac{\sigma^{2} h}{g}\left[\left(1+\frac{b}{a}\right) \frac{1}{\lambda_{0}{ }^{2}}-\sum_{n=1}^{\infty} \frac{C_{n}}{a} \cdot \frac{1}{\lambda_{n}{ }^{2}}\right] \\
& D_{r} \cosh \frac{r \pi l}{h}=d_{r}=2 \frac{a}{\pi^{2}} \cdot \frac{\sigma^{2} h}{g}\left[\left(1+\frac{b}{a}\right) \frac{1}{\lambda_{0}{ }^{2}+r^{2}}-\sum_{n=1}^{\infty} \frac{C_{n}}{a} \frac{1}{\lambda_{n}{ }^{2}-r^{2}}\right]
\end{aligned}
$$

となる。前と同様な入射波を仮定し, 式 (28) を用いると速度ポテンシャルは

$$
\begin{aligned}
& \phi_{1}(x, z ; t)=a e^{i \sigma t}\left[\left(e^{i k(x-l)}+\frac{b}{a} e^{-i k(x-l)}\right) \frac{\cosh k(z+h)}{\cosh k h}+\sum_{n=1}^{\infty} \frac{C_{n}}{a} e^{-k_{n}(x-l)} \frac{\cos k_{n}(z+h)}{\cos k_{n} h}\right] \ldots \\
& \phi_{2}(x, z ; t)=a e^{i \sigma t}\left[\frac{d_{0}}{2 a}+\sum_{r=1}^{\infty} \frac{d_{r}}{a} \frac{\cosh r H x / l}{\cosh r H} \cdot \cos \frac{r \pi z}{h}\right]
\end{aligned}
$$

反射率 $K_{r}$ は $|b / a|$ で与えられるが，これは恒等的に1に等しい。

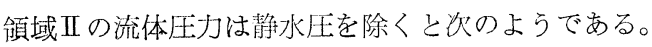




$$
\frac{p_{2}}{\alpha \rho g}=e^{i(k l+\sigma t)}\left\{\frac{d_{0}}{2 a}+\sum_{r=1}^{\infty} \frac{d_{r}}{a} \frac{\cosh r H x / l}{\cosh r H} \cdot \cos \frac{r \pi z}{h}\right\}
$$

水平板に作用する圧力 $p_{2}(z=0)$ とその全垝力 $P_{u}$ は次のようである。

$$
\begin{aligned}
& \frac{p_{2(z=0)}}{\rho g \alpha}=e^{i\left(k l_{+o t}\right)}\left\{\frac{d_{0}}{2 a}+\sum_{r=1}^{\infty} \frac{d_{r}}{a} \frac{\cosh r H x / l}{\cosh r H}\right\} \ldots \ldots . . . \\
& \left|\frac{P_{u}}{\rho g \alpha l}\right|=\left|\int_{0}^{l} \frac{p_{2(z=0)}}{\rho g \alpha l} d x\right|=\left|\frac{d_{0}}{2 a}+\sum_{r=1}^{\infty} \frac{d_{r}}{a} \cdot \frac{\tanh r H}{r H}\right| \ldots . .
\end{aligned}
$$

鈆直壁 $(x=0)$ に対する圧力 $p_{2(x=0)}$ とその全圧力 $P_{H}$ は次のよらである。

$$
\frac{p_{2(x=0)}}{\rho g \alpha}=e^{i(k l+\sigma t)}\left\{\frac{d_{0}}{2 a}+\sum_{n=1}^{\infty} \frac{d_{r}}{a} \frac{\cosh r \pi z / h}{\cosh r H}\right\},\left|\frac{P_{H}}{\rho g \alpha h}\right|=\left|\int_{-h}^{o} \frac{p_{2(x=0)}}{\rho g \alpha h} d z\right|=\left|\frac{d_{0}}{a}\right| .
$$

\section{2 枚の水平板をもつ防波堤と岸壁}

図一1 と 2 の破線で示すように, $z=-h / 2$ にさら に 1 枚の水平板がある場合には, 領域II速度ポテンシ ヤルには $z=-h / 2$ で $\partial \phi_{2} / \partial z=0$ の条件が加わる。この 場合は式 (6) と (35) に打り $r$ は偶数 $(0,2,4,6 \cdots)$ を取れば，上述の理論がそのまま適用される。同様にし て $z=0,-h / 3,-2 h / 3$ に 3 枚の板があるときは $r=3$, $6,9 \cdots \cdots$ とすれば良い。

\section{5. 計 算}

種々の $\sigma^{2} h / g=2 \pi h / L_{0}\left(L_{0}\right.$ は周期 $T$ に対する深海波 長）に対して式 (23) に定義した $\lambda_{0}$ と $\lambda_{n}$ を式 (8) に よって計算すると表一1のようである。これによって式 (24), (25) の $F_{r, n}$, と $\phi_{r, n}$ は $F_{r, r} \gg F_{r, n}, \phi_{r, r} \gg$

表一1 $\lambda_{0}$ and $\lambda_{n}$ for $\sigma^{2} h / g$

\begin{tabular}{|c|c|c|c|c|c|}
\hline$\lambda^{\sigma^{2} h} / g$ & 0.1 & 0.5 & 1.0 & 1.5 & 2.0 \\
\hline$\lambda_{0}$ & 0.10237 & 0.24564 & 0.38187 & 0.51624 & 0.65742 \\
$\lambda_{1}$ & 0.98977 & 0.94700 & 0.89075 & 0.83459 & 0.78263 \\
$\lambda_{2}$ & 1.99492 & 1.97440 & 1.94845 & 1.92251 & 1.89699 \\
$\lambda_{3}$ & 2.99662 & 2.98303 & 2.96597 & 2.98489 & 2.93194 \\
$\lambda_{4}$ & 3.99747 & 3.98730 & 3.97456 & 3.96182 & 3.94913 \\
$\lambda_{5}$ & 4.99794 & 4.98985 & 4.97968 & 4.96951 & 4.95953 \\
$\lambda_{6}$ & 5.99831 & 5.99155 & 5.98308 & 5.97462 & 5.96622 \\
\hline
\end{tabular}

$\phi_{r}, n$ の関係があるから,式(24)，(25)の解は近似計算に より容易に求められるが，電子計算機によって正しい解 を求めることは容易である。たとえば 1 枚板および 2 枚 板の防波堤について $\sigma^{2} h / g=1.0, l / h=1.0$ について $n$ お よび $r$ を 7 で取って計算すると表一2のよらである。

\section{6. 水平板防波堤に対する計算結果}

式 (32) による反射率 $K_{r}$ と通過率 $K_{t}$ を計算する と, 図一3 に示すようである。予期されるように $l / h$ と $\sigma^{2} h / g$ が大きいほど反射率は大きく通過率は小さい。 また板の総延長が等しい場合（たとえば1枚板の $l / h=$

\begin{tabular}{|c|c|c|c|}
\hline $\mathrm{n}$ & & $c_{n} / a$ & $g_{n} / a$ \\
\hline $\begin{array}{l}1 \\
2 \\
3 \\
4 \\
5 \\
6 \\
7\end{array}$ & $\begin{array}{l}-0.1340 \\
-0.03114 \\
-0.01392 \\
-0.007891 \\
-0.005077 \\
-0.003532 \\
-0.002582 \\
\end{array}$ & $\begin{array}{l}-0.03753 i \\
-0.01006 i \\
-0.004658 i \\
-0.002683 i \\
-0.001742 i \\
-0.001220 i \\
-0.0008751 i\end{array}$ & $\begin{array}{l}-0.05896+0.02837 i \\
-0.01050+0.008075 i \\
-0.004308+0.003788 i \\
-0.002340+0.002195 i \\
-0.001467+0.001430 i \\
-0.001003+0.001003 i \\
-0.0007238+0.0007374 i\end{array}$ \\
\hline $\mathbf{r}$ & & $d_{r} / a$ & er/a \\
\hline $\begin{array}{l}0 \\
1 \\
2 \\
3 \\
4 \\
5 \\
6 \\
7\end{array}$ & $\begin{array}{l}0.7063 \\
0.08366 \\
0.02246 \\
0.01004 \\
0.005633 \\
0.003594 \\
0.002488 \\
0.001823\end{array}$ & $\begin{array}{l}+0.03396 i \\
+0.003990 i \\
+0.001071 i \\
+0.0004788 i \\
+0.0002687 i \\
+0.0001714 i \\
+0.0001187 i \\
+0.00008699 i\end{array}$ & $\begin{array}{l}0.06392+0.05616 i \\
0.01522+0.01337 i \\
0.006499+0.005710 i \\
0.003563+0.003131 i \\
0.002242+0.001969 i \\
0.001537+0.001350 i \\
0.001118+0.0009827 i\end{array}$ \\
\hline
\end{tabular}
2.0 は 2 枚板の $l / h=1.0$ に対応する） は前者の方がす 表一2(a) $\sigma^{2} h / g=1.0, l / h=1.0$ (single plate) $b / a=0.5621+0.5434 i \quad f / a=0.4334-0.4482 i$

\begin{tabular}{|c|c|c|c|c|}
\hline $\mathrm{n}$ & \multicolumn{2}{|r|}{$c_{n} / a$} & \multicolumn{2}{|c|}{$\mathrm{Bn} / \mathrm{a}$} \\
\hline $\begin{array}{l}1 \\
2 \\
3 \\
4 \\
5 \\
6 \\
7\end{array}$ & $\begin{array}{l}-1.592 \\
0.08463 \\
0.6287 \\
-0.01199 \\
-0.1053 \\
0.0006480 \\
0.002819\end{array}$ & $\begin{array}{l}-1.422 i \\
+0.07888 i \\
+0.5925 i \\
-0.01136 i \\
-0.1001 i \\
+0.0006171 i \\
+0.002688 i\end{array}$ & $\begin{array}{l}-0.7140 \\
0.03229 \\
0.2284 \\
-0.004250 \\
-0.03680 \\
0.0002243 \\
0.0009689\end{array}$ & $\begin{array}{l}+0.08723 i \\
-0.01117 i \\
-0.09617 i \\
+0.001953 i \\
+0.01778 i \\
-0.0001119 i \\
-0.0004946 i\end{array}$ \\
\hline $\mathbf{r}$ & \multicolumn{2}{|r|}{$\mathrm{d} r / \mathrm{a}$} & \multicolumn{2}{|c|}{$e_{r} / a$} \\
\hline $\begin{array}{l}0 \\
2 \\
4 \\
6 \\
8 \\
10 \\
12 \\
14\end{array}$ & $\begin{array}{l}0.6614 \\
0.004674 \\
0.0005754 \\
0.0001629 \\
0.00006688 \\
0.00003387 \\
0.00001962 \\
0.00001247\end{array}$ & $\begin{array}{l}+0.3830 i \\
+0.002707 i \\
+0.0003332 i \\
+0.00009434 i \\
+0.00003873 i \\
+0.00001962 i \\
+0.00001136 i \\
+0.000007219 i\end{array}$ & $\begin{array}{l}0.002614 \\
0.0003059 \\
0.00008513 \\
0.00003464 \\
0.00001745 \\
0.00001007 \\
0.000006383\end{array}$ & $\begin{array}{l}+0.004496 i \\
+0.0005262 i \\
+0.0001464 i \\
+0.00005959 i \\
+0.00003002 i \\
+0.00001732 i \\
+0.00001098 i\end{array}$ \\
\hline
\end{tabular}

表—2(b) $\sigma^{2} h / g=1.0, l / h=1.0$ (double plate) $b / a=0.001452+0.8682 i \quad f / a=0.4963-0.0008301 i$

べての $\sigma^{2} h / g$ に対して $K_{r}$ は大きく $K_{t}$ は小さい。す なわち同じ延長の板では，これを水面に固定する方が波 に対して大きな抵抗を示すことになる。この傾向は $l / h$ と $\sigma^{2} h / g$ が大きいほど著しく，Kt について見ると 1 枚 板の $(l / h)_{1}=1.0$ と 2 枚板の $(l / h)_{2}=0.5$ では前者の $K_{t_{1}}$ が後者の $K_{t_{2}}$ の約 $5 \%$ 程度小さいにすぎないが, $(l / h)_{1}=2.0$ と $(l / h)_{2}=1.0$ では $K_{t_{1}} \approx 0.8 K_{t_{2}}\left(\sigma^{2} h / g=\right.$ $0.6), \approx 0.75 K_{t_{2}}\left(\sigma^{2} h / g=1.5\right)$ となる。これは水平板に より水面を固定することによって水平板の下の流体運動 を制限し，波に対して大きな慣性力を与えることにな 

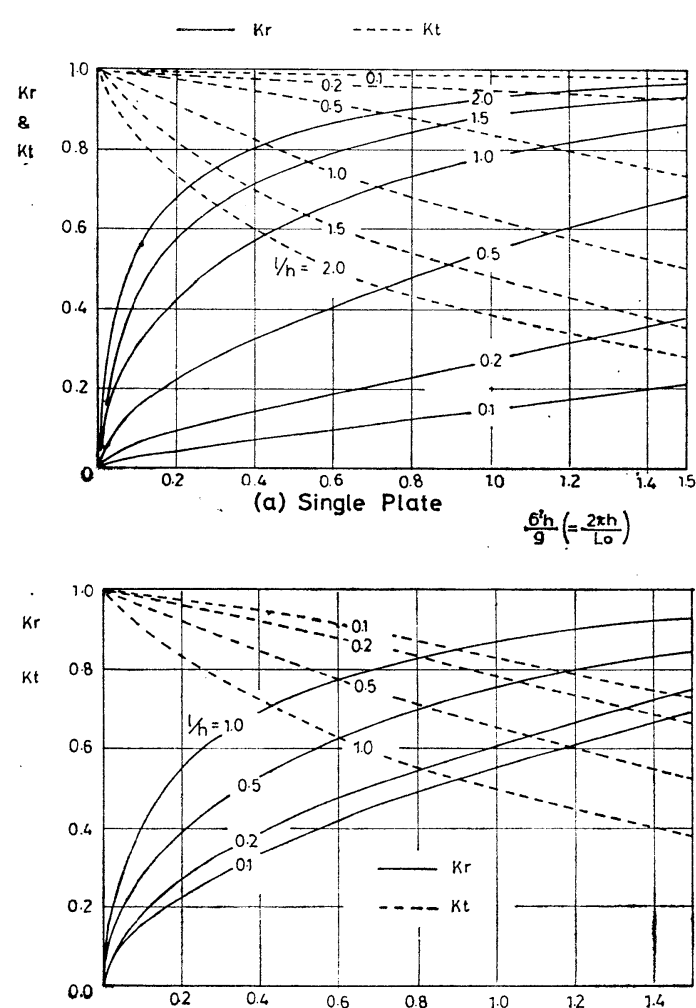

(b) Double Plates

図-3 Transmission and Reflection Coefficients (Breakwater)

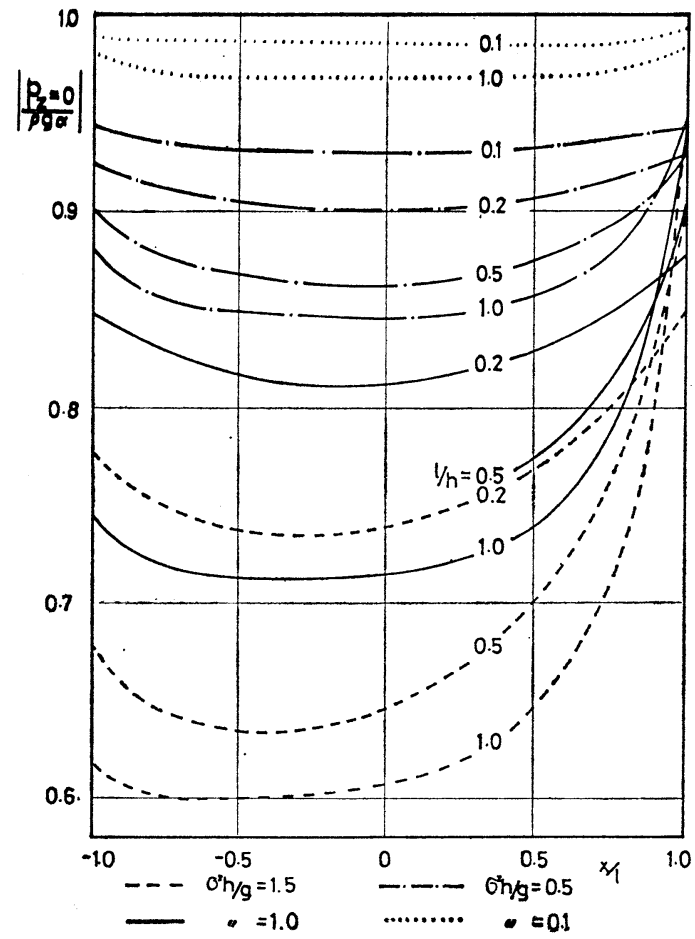

图-4 Pressure Distribution to Plate (Single Plate Breakwater)
り，波長の短い波に刘しては流体塊として作用し，半固 体防波堤としての性質を表わすことを意味している。1 枚板の場合 $l / h=2.0$ のときは， $\sigma^{2} h / g=0.5,1.0,1.5$ に対して $K_{t}=0.53 ， 0.38 ， 0.28$ であり，入射波のエネ ルギーのうちそれぞれ $28 \% ， 14 \%$ 扎よび $8 \%$ が通過す るにすぎないことになる。実際には水平板の前後端にお けるエネルギ一損失が大きく，これの計算値の 6〜7 割 以下となるから，多少の通過波を許す場合には防波堤と しての機能を十分果たし得ることがわかる。

種々の $l / h$ に打ける水平板に対する圧力分布を式(33) により計算すると図一4 のようで， $\sigma^{2} h / g$ と $l / h$ が小 さいほど圧力分布は一様になり, 図には示さないが, 2 枚板の場合には 図一4よりもさらに圧力分布は著しく 一様になる。図一5 は式 (34) による単位 振幅の入射 波による単位面積当りの䏛圧力であるが, $l / h$ と $\sigma^{2} h /$

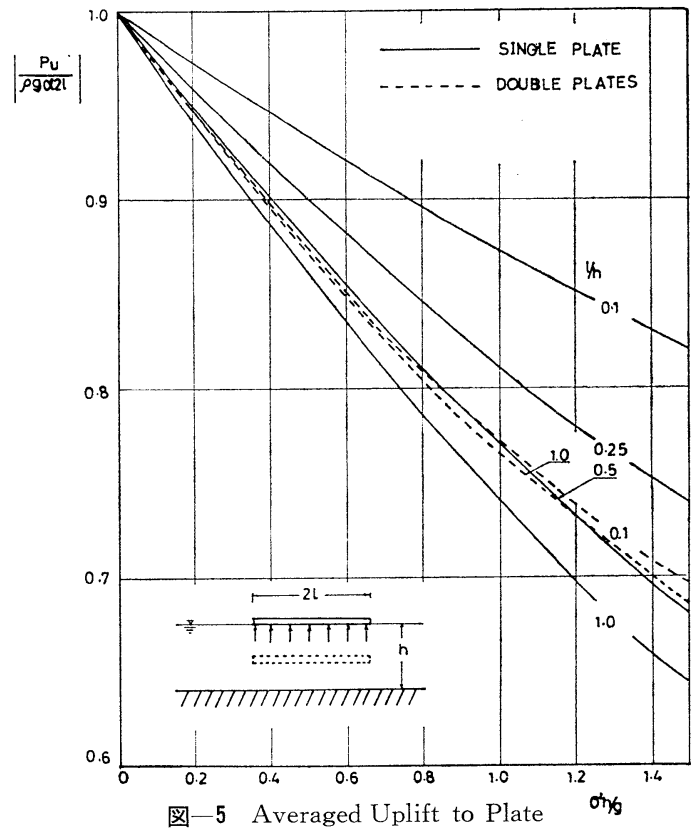

$g$ が大きいほど小さく，1 枚板と 2 枚板を比較すると後 者は $l / h$ にあまり関係なく, 前者の $l / h=0.5$ の場合に 近づくことがわかる。すなわち水中にある板は圧力分布 を一様化するとともに，平均圧力を均一化する作用をも つことが示唆される。

\section{7. 水平板をもつ岸壁に対する計算結果}

この場合については計算式は多少異なるが，前報告に 述べたので省略するが, 反射率はエネルギー損失を仮定 しないから常に 1 であり，また防波堤の場合と同様に水 平板と鉛直壁に対する圧力分布が求められ，水平板に対 する圧力の性質は防波堤の場合と類似であり，鉛直壁に 
対する圧力分布は $l / h$ が大きくなるとともに一様化され る。2 枚の板をもつときはさらにその傾问が著しくなる ことは防波堤の場合とまったく同様であることがわか る。水平板をもつ岸壁においては，境界条件による流体 運動の制約が防波堤の場合よりもさらに強く，水平板の 下の流体は波の入射に対しても板が長くなると静止の状 態に近づき，波の圧力をすべての方向に均一化する作用 を示すようになる。

\section{8. 水平板の下部に透過性物質がある場合の 防波堤と岸壁}

水平板の下部に捨石などを填充した場合は，その間げ きを流動する流体に対して抵抗を生ずることになる。か んたんのためこれを流速に比例すると仮定し，単位質量 の流体についての抵抗係数を $\mu$ ，空げき率を $V$ と寸る。 空げきを流れる流体の真の流速と圧力をそれぞれ $u, w$ および $p$ とすると連続および運動の方程式は次のよう である。

$$
\begin{aligned}
\frac{\partial u}{\partial x}+\frac{\partial w}{\partial z}=0, \frac{\partial u}{\partial t} & =-\frac{1}{\rho} \frac{\partial p}{\partial x}-\mu u, \\
\frac{\partial w}{\partial t} & =-\frac{1}{\rho} \frac{\partial p}{\partial z}-g-\mu w .
\end{aligned}
$$

この領域の空げき率が $V$ であるから，単位体積につ いての平均の流速と压力をそれぞれ $\bar{u}, \bar{\varpi}$ 打よび $\bar{D}$ と すると

$$
\bar{u}=V \cdot u, \bar{w}=V \cdot w, \quad \bar{p}=V \cdot p
$$

と考えることができこれについて式（44）を書き直す と

$$
\begin{array}{r}
\frac{\partial \bar{u}}{\partial x}+\frac{\partial \bar{w}}{\partial z}=0, \frac{\partial \bar{u}}{\partial t}=-\frac{1}{\rho} \cdot \frac{\partial \bar{p}}{\partial x}-\mu \bar{u}, \\
\frac{\partial \bar{w}}{\partial t}=-\frac{1}{\rho} \frac{\partial \bar{p}}{\partial z}-g V-\mu \bar{w} .
\end{array}
$$

この運動は速度ポテンシャル $\overline{b を ち ~}$

$$
\bar{u}=\partial \bar{\phi} / \partial x, \bar{w}=\partial \bar{\phi} / \partial z
$$

とすると, 圧力 $\bar{p}$ は次式で与えられる。

$$
\frac{\bar{p}}{\rho}=-\frac{\partial \bar{\phi}}{\partial t}-\mu \bar{\phi}-g V \cdot z
$$

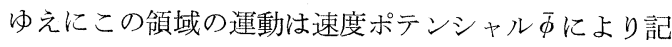
述され，しかも $\bar{\phi} は$ は式 (45) の第 1 式加ら Laplace の 方程式を満足するものとして決められる。

図一1に示寸ように, 水平板の下の領域については この $\bar{\phi}$ に対する境界条件は水面と水底で $\partial \bar{\phi} / \partial z=0$ で, $x= \pm l$ の境界面では質量流束の連続から

$$
\begin{aligned}
x=l \text { で } \partial \phi_{1} / \partial x & =\partial \bar{\phi} / \partial x, \\
x & =-l \text { で } \partial \phi_{3} / \partial x=\partial \bar{\phi} / \partial x \cdots
\end{aligned}
$$

となり，エネルギー流束の連続から $x= \pm l$ でそれぞれ $p_{1}=\bar{p} / V, p_{3}=\bar{p} / V$ となるべきで，したがって

$$
\begin{aligned}
& x=l \text { で } \quad \partial \phi_{1} / \partial t=\frac{1}{V}(\partial \bar{\phi} / \partial t+\mu \bar{\phi}) . \\
& x=-l \text { で } \quad \partial \phi_{3} / \partial t=\frac{1}{V}(\partial \bar{\phi} / \partial t+\mu \bar{\phi})
\end{aligned}
$$

各領域に対する速度ポテンシャルは式 (5)，(6)，(7) および (35) と同じ形で与えられるから,これらを式 (48)，(49)，(50) に代入し，式(23) と同じ記号を用いる と，防波堤に対しては式 (24)，(25) に対応して次式を 得る。

$$
\begin{aligned}
& \frac{b+f}{a}+i \sum_{n=1}^{\infty} \frac{\lambda_{0}{ }^{2}+r^{2}}{\lambda_{n}{ }^{2}-r^{2}} \frac{\lambda_{n}+P_{r} e^{i \nu}}{\lambda_{0}+P_{r} e^{i(\nu-\pi / 2)}} \cdot \frac{C_{n}+g_{n}}{a}=\frac{\lambda_{0}+P_{r} e^{i(\nu+\pi / 2)}}{\lambda_{0}+P_{r} e^{i(\nu-\pi / 2)}}, \quad(r=0,1,2 \cdots \cdots) \\
& \frac{b-f}{a}+i \sum_{n=1}^{\infty} \frac{\lambda_{0}{ }^{2}+r^{2}}{\lambda_{n}{ }^{2}-r^{2}} \frac{\lambda_{n}+Q_{r} e^{i \nu}}{\lambda_{0}+Q_{r} e^{i(\nu-\pi / 2)}} \cdot \frac{C_{n}-g_{n}}{a}=\frac{\lambda_{0}+Q_{r} e^{i(\nu+\pi / 2)}}{\lambda_{0}+Q_{r} e^{i(\nu-\pi / 2)}}, \quad(r=0,1,2 \cdots \cdots)
\end{aligned}
$$

ここで

$$
\begin{aligned}
& P_{r}=\frac{r V \tanh r H}{\beta}, Q_{r}=\frac{r V \operatorname{coth} r H}{\beta}, \beta=\sqrt{1+(\mu / \sigma)^{2}}, \nu=\tan ^{-1}(\mu / \sigma) \\
& P_{0}=0, Q_{0}=\lim _{r=0} r H V \cdot \operatorname{coth} r H /(\beta H)=V / \beta H \cdots
\end{aligned}
$$

式 (51)，(52) を連立方程式として解いて $b / a ， f / a ， C_{n} / a ， g_{n} / a$ が求まり， $D_{r}, E_{r}$ は次のように決まる。

$$
\begin{aligned}
& D_{0}=d_{0} / 2=\frac{V}{2 \beta} e^{i \nu} \cdot \frac{\sigma^{2} h}{g} \cdot \frac{a}{\pi^{2}}\left[\left(1+\frac{b+f}{a}\right) \frac{1}{\lambda_{0}{ }^{2}}-\sum_{n=1}^{\infty} \frac{1}{\lambda^{2}{ }_{n}} \frac{C_{n}+g_{n}}{a}\right] \\
& D_{r} \cosh r H=d_{r}=\frac{V}{\beta} e^{i \nu} \frac{\sigma^{2} h}{g} \cdot \frac{a}{\pi^{2}}\left[\left(1+\frac{b+f}{a}\right) \frac{1}{\lambda_{0}{ }^{2}+r^{2}}-\sum_{n=1}^{\infty} \frac{1}{\lambda_{n}{ }^{2}-r^{2}} \cdot \frac{C_{n}+g_{n}}{a}\right] \\
& E_{r} \sinh r H=e_{r}=\frac{V}{\beta} e^{i \nu} \frac{\sigma^{2} h}{g} \cdot \frac{a}{\pi^{2}}\left[\left(1+\frac{b-f}{a}\right) \frac{1}{\lambda_{0}{ }^{2}+r^{2}}-\sum_{n=1}^{\infty} \frac{1}{\lambda_{n}{ }^{2}-r^{2}} \cdot \frac{C_{n}-g_{n}}{a}\right] .
\end{aligned}
$$


こうして領域工と尚の水面波形と反射率 $K_{r}$ ，通過率 $K_{t}$ などは式 (51)，(52) からのb/a と $f / a ， C_{n} / a ， g_{n} / a$ により，式 (30)，(31)，(32）と同じ形で与えられ，領域II の速度ポテンシャルは式(54) を用いて式 (29) の第2 式の形で与えられる。人射波 $\zeta_{0}=\alpha \cos (k x+\sigma t)$ による流体圧力は静水生を除くと式 (47) の右辺第 2 項までで次の ようになる。

$$
\frac{p}{\rho g \alpha}=\frac{\beta}{V} e^{i(k l+\sigma t-\nu)}\left[\frac{d_{0}}{2 a}+\sum_{r=1}^{\infty}\left(\frac{d_{r}}{a} \frac{\cosh r H x / l}{\cosh r H}+\frac{e_{r}}{a} \frac{\sinh r H x / l}{\sinh r H}\right) \cos \frac{r \pi z}{h}\right]
$$

これから水半板に作用する圧力 $p_{2(z=0)}$ と全压力 $P_{u}$ はそれぞれ次のようである。

$$
\frac{p_{2(z=0)}}{\rho g \alpha}=\frac{\beta}{V} e^{i(\sigma t+k l-\nu)}\left[\frac{d_{0}}{2 a}+\sum_{r=1}^{\infty}\left(\frac{d_{r}}{a} \frac{\cosh r H x / l}{\cosh r H}+\frac{e_{r}}{a} \frac{\sinh r H x / l}{\sinh r H}\right)\right]
$$

$$
\left|\frac{P_{u}}{\rho g \alpha 2 l}\right|=\frac{\beta}{V}\left|\left(\frac{d_{0}}{2 a}+\sum_{r=1}^{\infty} \frac{d_{r}}{a} \frac{\tanh r H}{r H}\right)\right|
$$

以上は防波堤に対する計算式であるが，岸壁に対して は，3.に述べたことがそのままあてはまり，水平板が 2 林以上の場合も同様である。

\section{9. 透過性物質をもつ防波堤に対する計算結 果}

$\sigma^{2} h / g=1.0, \quad l / h=1.0, \quad V=0.5, \mu / \sigma=1.0$ に対する $b / a, f / a, C_{n} / a$ etc. を式 (51)，(52) で計算した例を示 すと表一3のようである。

表一3 $\quad \sigma^{2} h / g=1.0, \quad l / h=1.0, \quad V=0.5, \quad \mu / \sigma=1.0$ $b / a=0.7769+0.1685 i \quad f / a=0.1930-0.1239 i$

\begin{tabular}{|l|ll|ll|}
\hline$n$ & \multicolumn{3}{|c|}{$c_{n} / a$} & \multicolumn{2}{|c|}{$g_{n} / a$} \\
\hline$I$ & -0.06763 & $-0.05141 i$ & -0.02255 & $-0.009455 i$ \\
2 & -0.01620 & $-0.01236 i$ & -0.003733 & $-0.0008074 i$ \\
3 & -0.007329 & $-0.005580 i$ & -0.001490 & $-0.0001913 i$ \\
4 & -0.004184 & $-0.003178 i$ & -0.0007981 & $-0.00006291 i$ \\
5 & -0.002750 & $-0.002051 i$ & -0.0004964 & $-0.00002332 i$ \\
6 & -0.001888 & $-0.001430 i$ & -0.0003377 & $-0.000008349 i$ \\
7 & -0.001384 & $-0.001046 i$ & -0.0002429 & $-0.000002015 i$ \\
\hline & \multicolumn{3}{|c|}{$\mathrm{d} / \mathrm{a}$} & \multicolumn{3}{|c|}{$\mathrm{er} / \mathrm{a}$} \\
\hline 0 & 0.16771 & $-0.17753 i$ & & \\
$I$ & 0.03904 & $-0.02638 i$ & 0.028177 & $-0.03108 i$ \\
2 & 0.01071 & $-0.007101 i$ & 0.007753 & $-0.007868 i$ \\
3 & 0.004838 & $-0.003176 i$ & 0.003508 & $-0.003445 i$ \\
4 & 0.002734 & $-0.001784 i$ & 0.001984 & $-0.001915 i$ \\
5 & 0.001753 & $-0.001138 i$ & 0.001273 & $-0.001215 i$ \\
6 & 0.001218 & $-0.0007888 i$ & 0.0008849 & $-0.0008382 i$ \\
7 & 0.0008950 & $-0.0005782 i$ & 0.0006505 & $-0.0006126 i$ \\
\hline
\end{tabular}

前述の計算式により $l / h=1.0, V=0.5$ の場合につい て， $\mu / \sigma$ をパラメーターとして反射率 $K_{r}$ と通過率 $K_{t}$ を計算すると図一6 のようである。子期されるように $\mu / \sigma$ の増加とともに $K_{r}$ は増加し $K_{t}$ は減少する。また $\mu / \sigma=0$ のときは 図一3 (a) とくらべるとわかるように 1 枚板の $l / h=2.0$ の場合と一致する。これは空げき率 をもつ物質を填充することによる空げきの効果は堤体幅 $l$ を増加させ $l / V$ の幅をもたせることに相当し, 抵抗值 $\mu / \sigma$ の効果注入射波に対する抵抗を生じ，また堤体内で エネルギー損失を生じて通過波を減少させることを意味 している。すなわち防波堤においては空げき率を与える ことは堤体幅を増加して反射効果をあげることによって

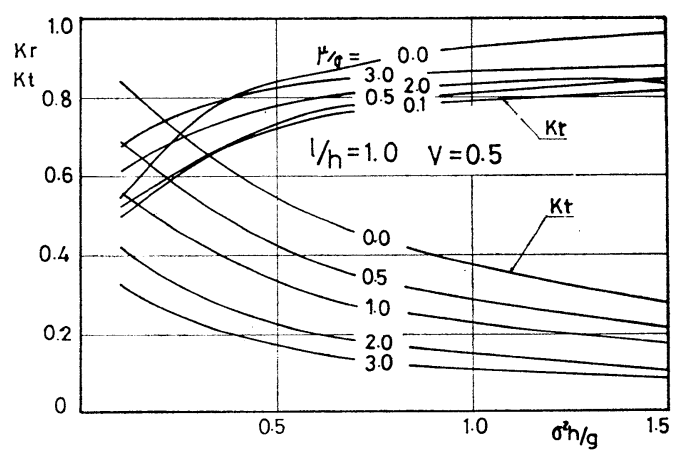

図-6 $K r$ and $K t$ of Breakwater

通過波を減少させることになり，流体抵抗を与えること により，堤体内部でのエネルギ一損失の効果によって反 射波も通過波もともに减少させることになるが，さらに 抵抗が大きくなると再び反射効果が大きくなって, 通過 波は減少することになる。

次に式 (56) によって水平板に作用する圧力分布を計 算すると 図一7 のようである。図-4の $l / h=1.0$ の場 合とくらべるとわかるように, 透過性物質のない場合 にくらべて圧力分布の変化は著しい。 $\sigma^{2} h / g$ が大きいほ どこの傾向は著しくなるのは，前述のように空げき率が 堤体幅を增加させる効果をもつことと一致した傾向であ る。すなわち中間に水平板を㨀入すると圧力分布は均一 化されるに反して，透過性物質をおくと，圧力分布の変 化は反対に大きくなることになる。しかし式 (57) によ る全圧力は，透過性物質のない場合の值とほとんど変わ らない。

\section{0. 透過性物質をもつ岸壁に対する計算結果}

上と類似の計算を岸壁について行ない，その反射率 $K_{r}$ を求めると図一8 のようである。 $K_{r}$ は $\sigma^{2} h / g$ の 増加に伴って減少することになるが， $\mu / \sigma$ による変化は 一様でなく， $\sigma^{2} h / g$ の大きいところでは $\mu / \sigma$ が 1.0 2.0 において $K_{r}$ の最小が現われる。すなわち反射率は $\sigma^{2} h /$ $g$ により決まる特定の $\mu / \sigma$ についてもっとも小さく, それ以外の $\mu / \sigma$ に対してはかえって大きい反射率が現 


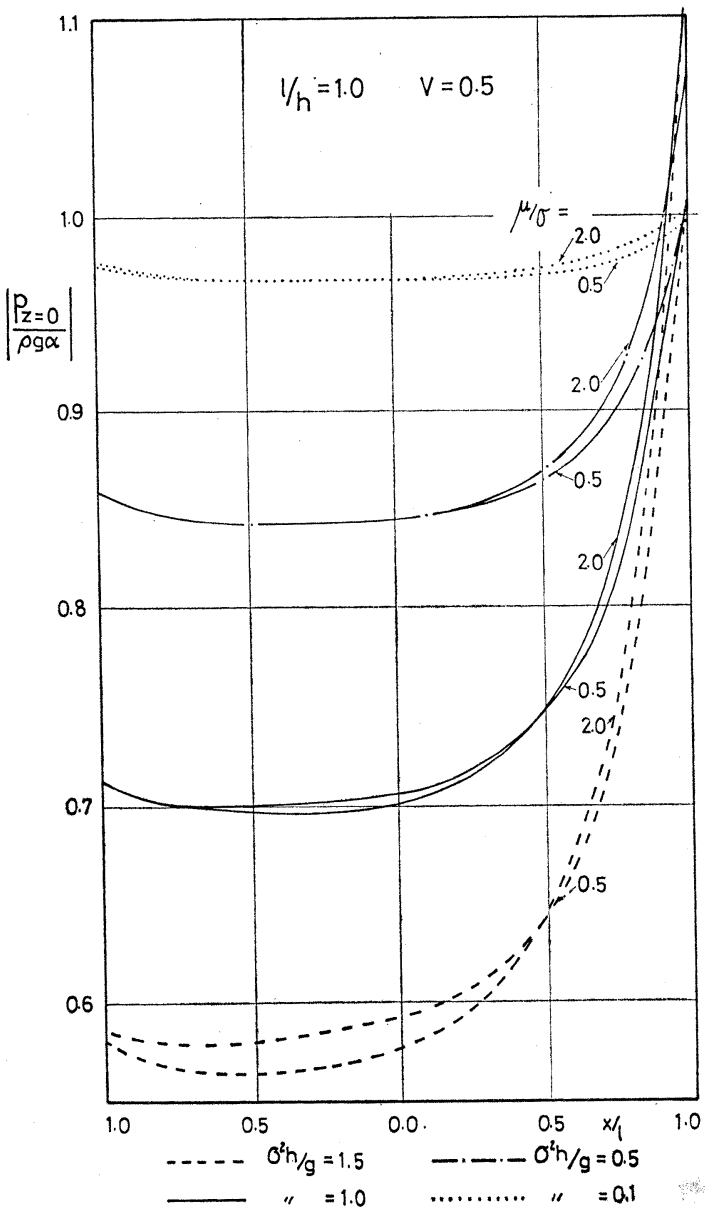

図-7 Pressure Distribution to Plate(Breakwater)

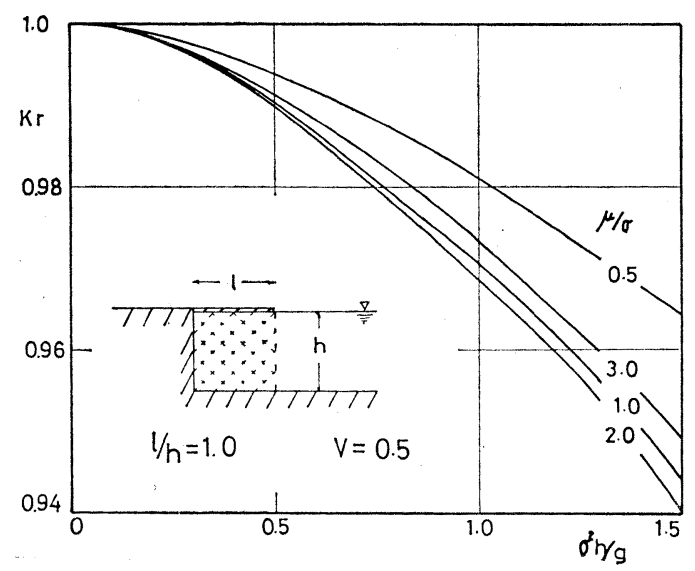

図-8 Reflection Coefficient of Quay Wall

われることになる。なお種々の $l / h$ すなわち岸壁幅につ いて計算して見ると $l / h \geqq 1.0$ では $K_{r}$ はほとんど一定 である。このことと $K_{r}$ の值自体が普通の $\sigma^{2} h / g$ に対し ては 0.94 以上という大きな值に止まり，反射率の低下 があまり起こらないことは，この岸壁内部での流速が小

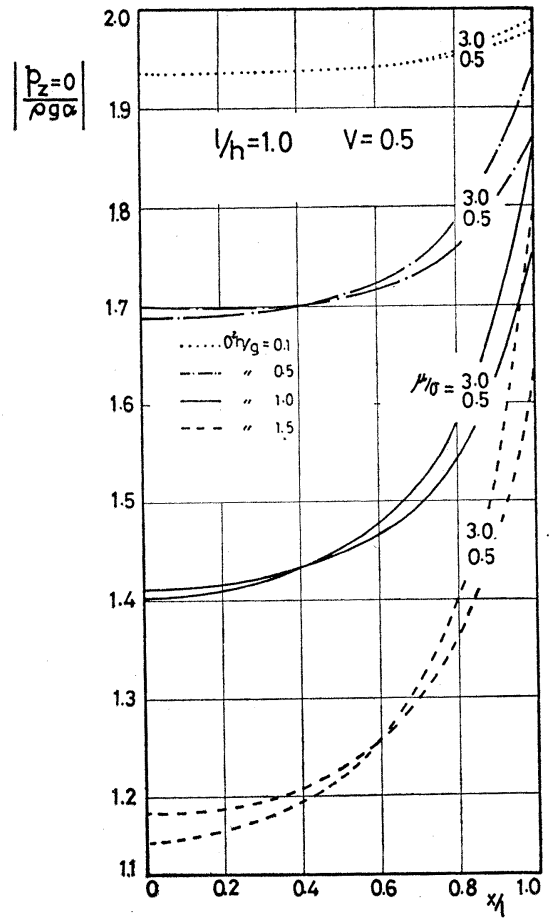

图-9 Pressure Distribution to Plate

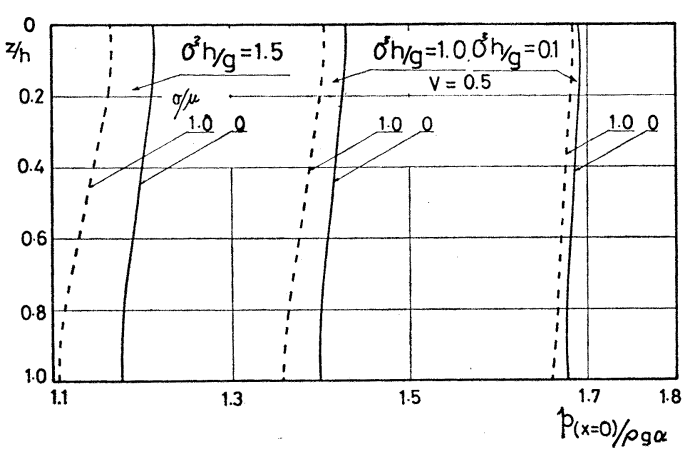

図-10 Pressure Distribution to Vertical Wall

さいため，抵抗によるエネルギー損失が生じ難いという ことおよびエネルギーの損失は岸壁前端の限られた領域 においてしか起こらないことを意味する。

圧力分布について見ると，水平板に対しては 図一-9 に示すようで防波堤の場合と同様に水平板前端付近の压 力集中の傾向が強くなる。鉛直壁面に対しては 図一10 に示すようで透過性物質のない場合と類似の分布であ る。

\section{1.むすび}

水面に固定された水平板に対する長波の作用は Sto$\operatorname{ker}(1957)$ によって紹介されており，また水平板をもつ 岸壁については Friedrichs-Levy による研究がある。こ 
こではこれらと異なった方法による比較的簡単な解法を 試みた結果を述べたもので，岸壁に対しては前報告で実 験值との比較を示したが，防波堤については 2 3 の場 合について（透過性物質のないとき）実験值との比較を 行なって計算の妥当なことを確かめた。これらの比較に ついては次の報告で述べることにする。
参考文 献

1）井島・尾崎・松尾・小林 (1969)：“直立消波岸壁佂関す 研究 (1) 一水平板岸壁について-”, 第 16 回海岸工学 講演会講演集

2) Stoker, J. J. (1957) : "Water Waves", Interscience Publishers, New-York

3) Friedrichs, K. O. \& H. Levy (1948) : "The Dock Problem", Communications on Pure and Applied Mothematics, Vol. 1. 